This item was submitted to Loughborough's Research Repository by the author.

Items in Figshare are protected by copyright, with all rights reserved, unless otherwise indicated.

\title{
Application of FRC constitutive models to modelling of slabs
}

PLEASE CITE THE PUBLISHED VERSION

https://doi.org/10.1617/s11527-014-0369-5

PUBLISHER

Springer $@$ RILEM

VERSION

AM (Accepted Manuscript)

PUBLISHER STATEMENT

This work is made available according to the conditions of the Creative Commons Attribution-NonCommercialNoDerivatives 4.0 International (CC BY-NC-ND 4.0) licence. Full details of this licence are available at: https://creativecommons.org/licenses/by-nc-nd/4.0/

\section{LICENCE}

CC BY-NC-ND 4.0

\section{REPOSITORY RECORD}

Blanco, Ana, Sergio H. Cavalaro, Albert De la Fuente, S. Grunewald, C.B.M. Blom, and J.C. Walraven. 2019. "Application of FRC Constitutive Models to Modelling of Slabs". figshare. https://hdl.handle.net/2134/32309. 


\title{
Application of FRC constitutive models to the modelling of slabs
}

\author{
A. Blanco ${ }^{a *}$, S. Cavalaro ${ }^{a}$ A. de la Fuentea, S. Grünewaldb, C.B.M Blomb ${ }^{b}$, J.C. Walraven ${ }^{b}$
}

\begin{abstract}
${ }^{a}$ Department of Construction Engineering, Universitat Politècnica de Catalunya, UPC, Jordi Girona 1-3, 08034 Barcelona, Spain. ${ }^{b}$ Department of Structural and Building Engineering, Concrete Structures Group, TU Delft, Stevinweg 1, 2628CN Delft, The Netherlands.

* Corresponding author. Tel.: +34-93-401-7347; fax: +34-93-401-1036; e-mail: ana.blanco@upc.edu
\end{abstract}

\begin{abstract}
Fibre reinforcement technology has advanced significantly in the past years and, as a result, expanded to different applications. In particular, steel fibre reinforced concrete (SFRC) has been successfully employed in flat slabs of several buildings in Europe with the fibres as the only reinforcement. However, the design methods for fibre reinforced concrete (FRC) structures do not consider the differences that may cause the use of tests for the characterization of the material that are not representative of the structural behaviour and the fibre orientation of the real-scale element. In this regard, the present paper shows a numerical study in which two constitutive models for FRC based on the bending test are applied to estimate the flexural behaviour of full-scale slabs with different dimensions. Likewise, a parametric study is conducted to analyse how the parameters of these constitutive models affect the flexural response of the slabs and a numerical fit of the experimental data is performed. The finite element simulations with the constitutive models overestimate the experimental results. The parametric study also reveals that the parameter $\sigma_{2}$ (stress after cracking) is particularly influent in the response. Furthermore, an enhanced sectional behaviour of the slabs was observed as the width of the slabs increased.
\end{abstract}

Keywords: SFRC; slab; design; fibre; modelling

\section{Introduction}

Steel fibre reinforced concrete (SFRC) is used in a wide range of structures such as pavements (Sorelli and Plizzari 2006), tunnel lining segments (Plizzari and Tiberti 2006; de la Fuente et al. 2012) and flat slabs (Destrée and Mandl 2008). Evidently, all these elements present shapes and casting procedures different from the ones used in the standard specimens employed to characterize the material (small beams subjected to bending according to EN 14651:2005 (CEN 2005b) or NBN B 15-238 (IBN 1992)). Therefore, even if the same type of concrete is used, it is reasonable to assume that the fibre orientation and the sectional structural response might be different in the real-scale element and in the beam test specimen.

In line with that, a study on the mechanical performance of SFRC flat slabs (Michels et al. 2012) concluded that the fibres were less oriented and the residual strength decreased as the thickness of the element increased. The study revealed the need to introduce realistic geometry factors in the design to account for these differences. Nevertheless, many codes and guidelines for the design of SFRC still do not include parameters related with possible variations in the structural response due to special geometries, which should be particularly noticeable in slab-like elements. Instead, the results from the beam test are directly applied to obtain the constitutive equations from the material, entailing the assumption that the sectional response from the beam test is maintained in the real-scale element. Such hypothesis might lead to either unsafe or conservative design in some cases. 
Taking that into account, two European guidelines - the German guidelines (DBV 2001) and the RILEM recommendations (RILEM TC162-TDF 2003) - already introduced a size factor in order to consider the influence of the height of the element over the bending behaviour of the cross-section. More recently, the Model Code 2010 (fib 2010) proposed an orientation factor that modifies the performance of the SFRC depending on the favourable or unfavourable effect of the orientation on the structural response of the real-scale element. However, specific values are not suggested.

To support this novel view in the design of SFRC elements, it is necessary to evaluate the repercussion of using more traditional codes that do not include correction factors in the prediction of the behaviour of SFRC structures. It is also important to evaluate the influence of the dimensions of the structure, taking, as a reference, the results of experimental programs conducted with real-scale elements.

In this context, the main objective of this paper is to apply the current constitutive models to estimate the flexural response of real-scale slabs with different dimensions and to assess the variations between the experimental and estimated behaviours. Furthermore, a parametric study is conducted to analyse the influence of the parameters of the constitutive models on the structural response of the slabs. The results derived from this analysis help to explain why it is necessary to include correction factors towards a more efficient design of SFRC elements.

\section{Numerical simulation}

The flexural tests on real-scale slabs presented by Blanco (2013) were modelled with two different trilinear models included in the RILEM recommendations (RILEM TC162-TDF 2003) and in the Spanish code EHE-08 (CPH 2008). Notice that only constitutive models that do not account for fibre orientation were used in order to evaluate the importance of this aspect in the design of slabs. Prior to the description of the FEM model, a short background on the test setup of the slabs is provided to enable the comprehension of the assumptions made in the modelling.

\subsection{Background}

Slabs with $3.0 \mathrm{~m}$ of length, $0.2 \mathrm{~m}$ of thickness and widths of $1.5 \mathrm{~m}, 2.0 \mathrm{~m}$ or $3.0 \mathrm{~m}$ were tested. For each size, two slabs were cast and characterized. According to the notation adopted, the slabs were either small (S), medium (M) or large (L) depending on their width $(1.5 \mathrm{~m}, 2.0 \mathrm{~m}$ or $3.0 \mathrm{~m}$, respectively). The letter A or B was appended to the notation in order to identify the elements of each pair (e.g. S_A or L_B).

The concrete mix used to cast the slabs contained $40 \mathrm{~kg} / \mathrm{m}^{3}$ of hooked-end steel fibres Dramix@ RC80/50BN and was designed to obtain a consistency close to self-compactability. The mix was poured from the centre of the formwork. Once the pouring of the material was finished, the walls of the formwork were vibrated externally during approximately 20 seconds to ensure a uniform distribution of the concrete in the mould. 
The slabs were placed over steel trestles located close to the borders and extending over the central half of the sides (see Figure 1a). This setup enabled a hyperstatic support condition that allows an internal redistribution of forces and the contribution of fibers in more than one direction. The load was applied at the center of the slab by means of a piston connected with servo-hydraulic jack. Neoprene sheets were placed between the piston and the top of the slab to ensure full contact with the loading surface. To limit the contact area and to guarantee a more uniform load transmission to the supports, neoprene sheets were also placed between the slab and the steel trestles.

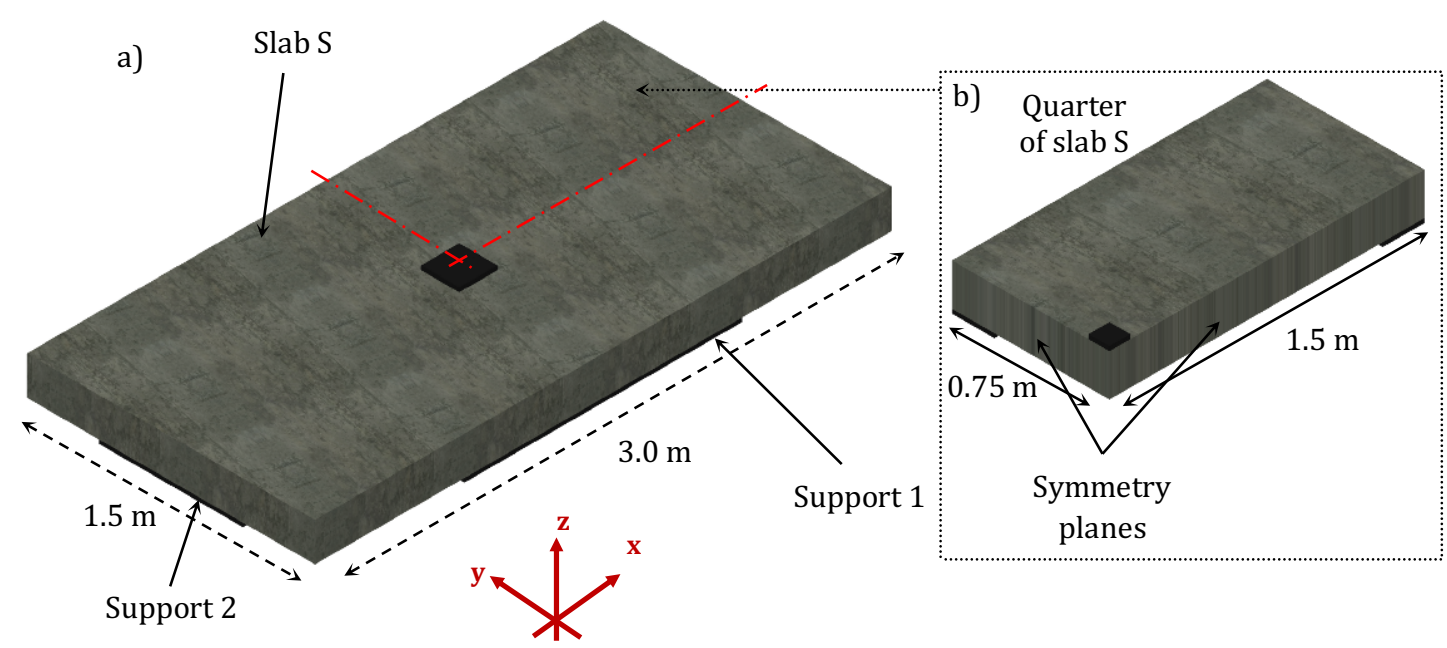

Figure 1. Detail of a) geometry of the slab $S$ and b) model of one quarter of slab used in the numerical simulation.

The load applied (P), the displacement of the piston and the deflection $(\delta)$ at different locations of the slab were measured throughout the test. The assessment of the deflections was performed with 14 magnetostrictive displacement transducers located at the axis of the element and at the supports. After the test, the crack pattern was assessed and the loaddeflection curves ( $P-\delta$ curves) were obtained. Although deflections were measured at several points, to simplify the presentation of results only the deflection at the centre of the slab is presented.

\subsection{Description of the FEM model}

The numerical simulation of the test was performed in the finite element software ATENA 4.3.1g (Cervenka 2000) that has specific material models for concrete and elements for a 3D analysis. This was mandatory in the present case given that the test configuration should allow redistribution of moments and the contribution of fibres in more than one direction, which requires a 3D analysis of the slabs. For that reason, tetrahedral solid elements were used in the mesh.

The tensile behaviour of concrete was modelled by non-linear fracture mechanisms combined with the crack band method and the smeared crack approach. In the case of SFRC, specific material stress-strain diagrams were defined in compression and in tension. The crack band size was automatically calculated by ATENA and the characteristic size or length used to estimate the strain was defined according with other works from the literature. 
Several studies propose the use of a constant value for the characteristic size (Ultkjaer et al. 1995, Pedersen 1996, Iyengar 1998, Kooiman 2000, AFGC-SETRA 2002, RILEM 2002, Massicotte 2004, CNR-DT 204 2006, fib 2010), whereas others (Casanova and Rossi 1997) suggest that it should vary with the load level. In line with that, the Italian standard UNI11188 (UNI 2004) proposes the consideration of several characteristic sizes depending to the loading phase of the element (micro-cracking phase, macro-cracking hardening phase and at crack localization). Nonetheless, de Montaignac et al. (2011) indicate that adopting such a refinement is not required for the design. The authors suggest that the use of a single constant value already provides satisfactory results. Taking that into account, a constant characteristic size was used in the present study.

According to UNI11188, the value adopted for the characteristic size should depend on the objective of the calculations. Small values should be chosen if the objective is to reproduce accurately global observations of the structural behavior such as deflection, average crack width or curvature for a certain load level. For the assessment of the structural response of SFRC without any other type of reinforcement, recommended characteristic sizes may range from half $(\mathrm{h})$ to twice $(2 \mathrm{~h})$ the mid-height of the specimen (de Montaignac et al. 2011). This range is consistent with the finite element models that define the extent of the crack influence zone close to the member depth on both sides of the crack (Kooiman 2000). Considering the aim of the present study, the characteristic size selected to estimate the strain was half the height of the notched beam, as suggested by Ultkjaer et al. (1995), Pedersen (1996), Iyengar (1998), Kooiman (2000), RILEM 2002, de Montaignac et al. (2011).

Another important point regarding the model is the definition of the size of the finite element. The idea was to use a sufficiently refined mesh that reproduces well the localized cracking of the SFRC observed experimentally. However, this may also increase considerably the time dedicated to the calculation of each model, which is an especially relevant issue when it comes to parametric studies. In this context, two possibilities were considered: the simulation of the complete slab or the simulation of only one quarter of a slab adopting boundary conditions that account for the initial symmetry of the element. Although the last approach allows increasing the refinement of the mesh without compromising the time of calculation, it also has possible drawbacks. For once, it could lead to different results since the crack pattern of the complete slab would not be symmetric in reality.

To evaluate this issue, the slabs $\mathrm{S}, \mathrm{M}$ and $\mathrm{L}$ were simulated considering the complete element and only one quarter. Figure 2 presents the results of the simulations, which revealed that both approaches yield approximately the same $P-\delta$ curves despite the simplification adopted in the reduced model. Based on such outcome, for efficiency purposes and in order to use a more refined mesh discretization, the authors considered appropriate to use the latter. As an example, Figure 1a depicts the reduced model of Slab S. 


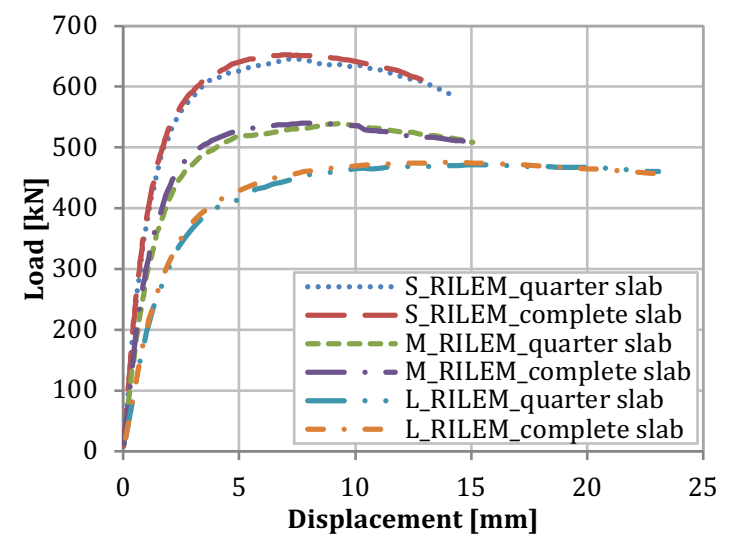

Figure 2. P- $\delta$ curves for slabs $S, M$ and $L$ for the reduced and complete models.

During preliminary studies, it was observed that the precise simulation of the supports was mandatory in order to obtain a $P-\delta$ curve with a shape close to the experimental one. For that, the neoprene sheets placed at the loading point and at the support were explicitly simulated using the properties obtained experimentally in the tests of the EN 1337-3:2005 (CEN 2005a). Since the maximum compressions and the strains at the supports were considerably small, it was assumed that the material works in an almost linear elastic regime according with the Hooke's law. Furthermore, the friction between the slab and the support was simulated as well as the mixed stress state produced as a result of it. For that reason, interface elements that follow a Coulomb friction model were added between the slab and the neoprene sheets.

Simply supported conditions were imposed by restraining the vertical displacement of the bottom face of the neoprene located in supports 1 and 2 (see Figure 1a). The displacement perpendicular to the symmetry planes shown in Figure $1 \mathrm{~b}$ were also restrained. The load case consisted of a vertical displacement acting simultaneously at all nodes on top face of the loading surface in contact with the piston.

Table 1 presents the dimensions of the slab, the neoprene sheets at supports and at loading point for the reduced model. Table 2 shows the material properties of the SFRC, the neoprene and the interface elements considered. Notice that the properties of the SFRC were defined according to the tests of compressive strength (UNE 83507:2004 (AENOR 2004)), modulus of elasticity (UNE 83316:1996 (AENOR 1996)) and residual strength (EN 14651:2005 (CEN 2005)) performed by Blanco (2013) in the same batch of concrete used to cast the slabs.

Table 1. Dimensions of the elements in the models.

\begin{tabular}{clccc}
\hline Model & \multicolumn{1}{c}{ Element } & Length [mm] & Width [mm] & Height [mm] \\
\hline \multirow{5}{*}{ Model S } & Slab & 1500 & 750 & 200 \\
& Neoprene sheet at loading point & 100 & 100 & 20 \\
& Neoprene sheet at support 1 & 750 & 200 & 20 \\
& Neoprene sheet at support 2 & 375 & 200 & 20 \\
\hline \multirow{5}{*}{ Model M } & Slab & 1500 & 1000 & 200 \\
& Neoprene sheet at loading point & 100 & 100 & 20 \\
& Neoprene sheet at support 1 & 750 & 200 & 20 \\
& Neoprene sheet at support 2 & 500 & 200 & 20 \\
\hline \multirow{5}{*}{ Model L } & Neoprene sheet at loading point & 1500 & 1500 & 200 \\
& Neoprene sheet at support 1 & 750 & 100 & 20 \\
& Neoprene sheet at support 2 & 750 & 200 & 20 \\
& & & 200 & 20 \\
\hline
\end{tabular}


Table 2. Properties of the material defined in the models.

\begin{tabular}{|c|c|c|c|c|}
\hline Model & Model part & Material properties & Value & Reference \\
\hline \multirow{7}{*}{$\begin{array}{l}\text { Common } \\
\text { properties } \\
\text { for all } \\
\text { models }\end{array}$} & \multirow{2}{*}{$\begin{array}{l}\text { Neoprene } \\
\text { sheets }\end{array}$} & Average modulus of elasticity [MPa] & 35.0 & Experimentally \\
\hline & & Poisson ratio [-] & 0.3 & - \\
\hline & \multirow{5}{*}{$\begin{array}{l}\text { Interface } \\
\text { material }\end{array}$} & Normal stiffness $\left[\mathrm{MN} / \mathrm{m}^{3}\right]$ & $2.0 \cdot 10^{8}$ & - \\
\hline & & Tangential stiffness $\left[\mathrm{MN} / \mathrm{m}^{3}\right]$ & $2.0 \cdot 10^{8}$ & - \\
\hline & & Cohesion $[\mathrm{MPa}]$ & 1.0 & - \\
\hline & & Friction coefficient & 0.1 & - \\
\hline & & Cut-off traction stress [MPa] & 0.3 & - \\
\hline \multirow{10}{*}{ Model S } & \multirow{10}{*}{ SFRC slab } & Average compressive strength [MPa] & 46.8 & Experimentally \\
\hline & & Average modulus of elasticity [GPa] & 30.6 & Experimentally \\
\hline & & Poisson ratio $[-]$ & 0.2 & Eurocode 2 \\
\hline & & Average tensile strength $\sigma_{1}[\mathrm{MPa}]$ & $5.6 / 2.9$ & RILEM / EHE \\
\hline & & Average residual strength $\sigma_{2}[\mathrm{MPa}]$ & $2.5 / 2.8$ & RILEM / EHE \\
\hline & & Average residual strength $\sigma_{3}[\mathrm{MPa}]$ & $2.2 / 1.7$ & RILEM / EHE \\
\hline & & Average strain $\varepsilon_{1}[\% o]$ & $0.2 / 0.1$ & RILEM / EHE \\
\hline & & Average strain $\varepsilon_{2}[\% 0]$ & $0.3 / 0.2$ & RILEM / EHE \\
\hline & & Average strain $\varepsilon_{3}[\% 0]$ & $25.0 / 20.0$ & RILEM / EHE \\
\hline & & Tension characteristic size $[\mathrm{m}]$ & 0.0625 & $\begin{array}{l}\text { Pederson (1996), } \\
\text { Kooiman (2000); } \\
\text { ATENA Manual, etc. }\end{array}$ \\
\hline \multirow{10}{*}{$\begin{array}{l}\text { Model M } \\
\quad+ \\
\text { Model L }\end{array}$} & \multirow{10}{*}{ SFRC slab } & Average compressive strength [MPa] & 46.7 & - \\
\hline & & Average modulus of elasticity [GPa] & 29.0 & - \\
\hline & & Poisson ratio [-] & 0.2 & Eurocode 2 \\
\hline & & Average tensile strength $\sigma_{1}[\mathrm{MPa}]$ & $5.6 / 2.9$ & RILEM / EHE \\
\hline & & Average residual strength $\sigma_{2}[\mathrm{MPa}]$ & $2.5 / 2.8$ & RILEM / EHE \\
\hline & & Average residual strength $\sigma_{3}[\mathrm{MPa}]$ & $2.2 / 1.7$ & RILEM / EHE \\
\hline & & Average strain $\varepsilon_{1}[\% 0]$ & $0.2 / 0.1$ & RILEM / EHE \\
\hline & & Average strain $\varepsilon_{2}[\% 0]$ & $0.3 / 0.2$ & RILEM / EHE \\
\hline & & Average strain $\varepsilon_{3}[\% 0]$ & $25.0 / 20.0$ & RILEM / EHE \\
\hline & & Tension characteristic size $[\mathrm{m}]$ & 0.0625 & ATENA Manual \\
\hline
\end{tabular}

The simulations were conducted with two different trilinear constitutive models for the SFRC: the diagram proposed by the RILEM (RILEM TC162-TDF 2003) - a reference for many years despite overestimating the post-cracking response of SFRC (Barros et al. 2005; Tlemat et al. 2006) - and the diagram proposed by EHE-08 (CPH 2008) - the most recent trilinear model in European codes. Figure 3a depicts the parameters required for the definition of the stress-strain diagram in these guidelines, while Figure $3 \mathrm{~b}$ shows the differences observed after applying both of them to the same results of the bending test EN 14651:2005. The most noticeable difference is related with the estimated tensile strength and the value of the ultimate strain. The latter is 25\% in the RILEM and 20\%o in the EHE-08 for elements subjected to bending loads.
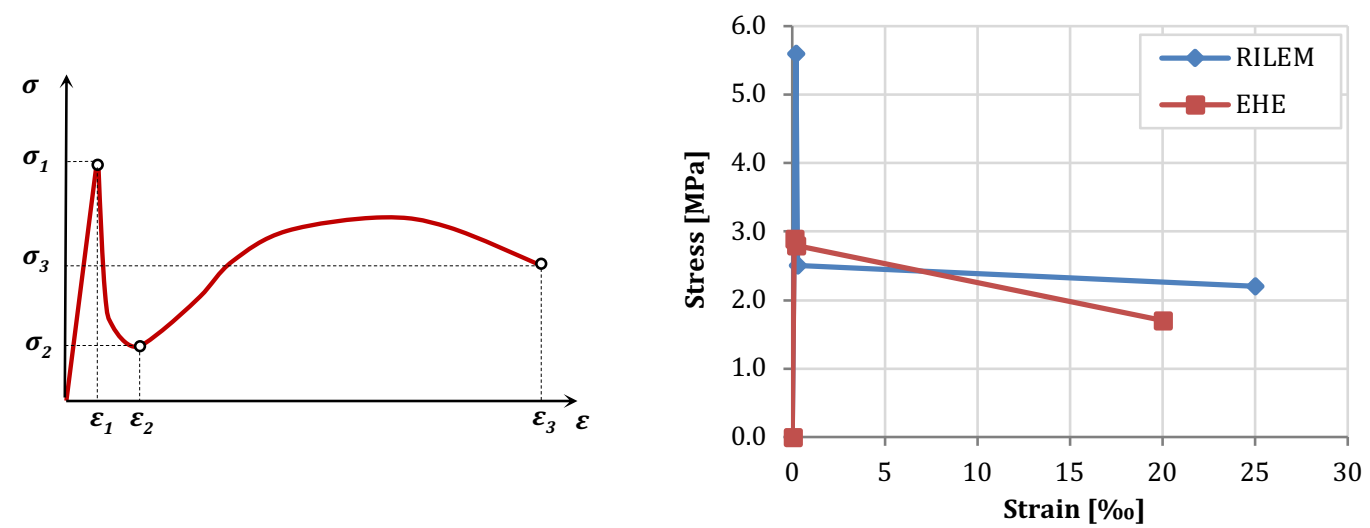

Figure 3. Constitutive models of the RILEM and EHE: a) basic parameters and b) differences in curves. 


\section{Results}

In the following sections, the results obtained in the finite element model are compared with the ones measured in the experimental program.

\subsection{Crack patterns}

Figure 4 shows the crack patterns obtained with the numerical simulations and those observed in the laboratory tests for the same deflection. As an example, only the numerical results obtained with the model from the EHE are depicted in Figure 4 given that the models from the RILEM provided identical trends.
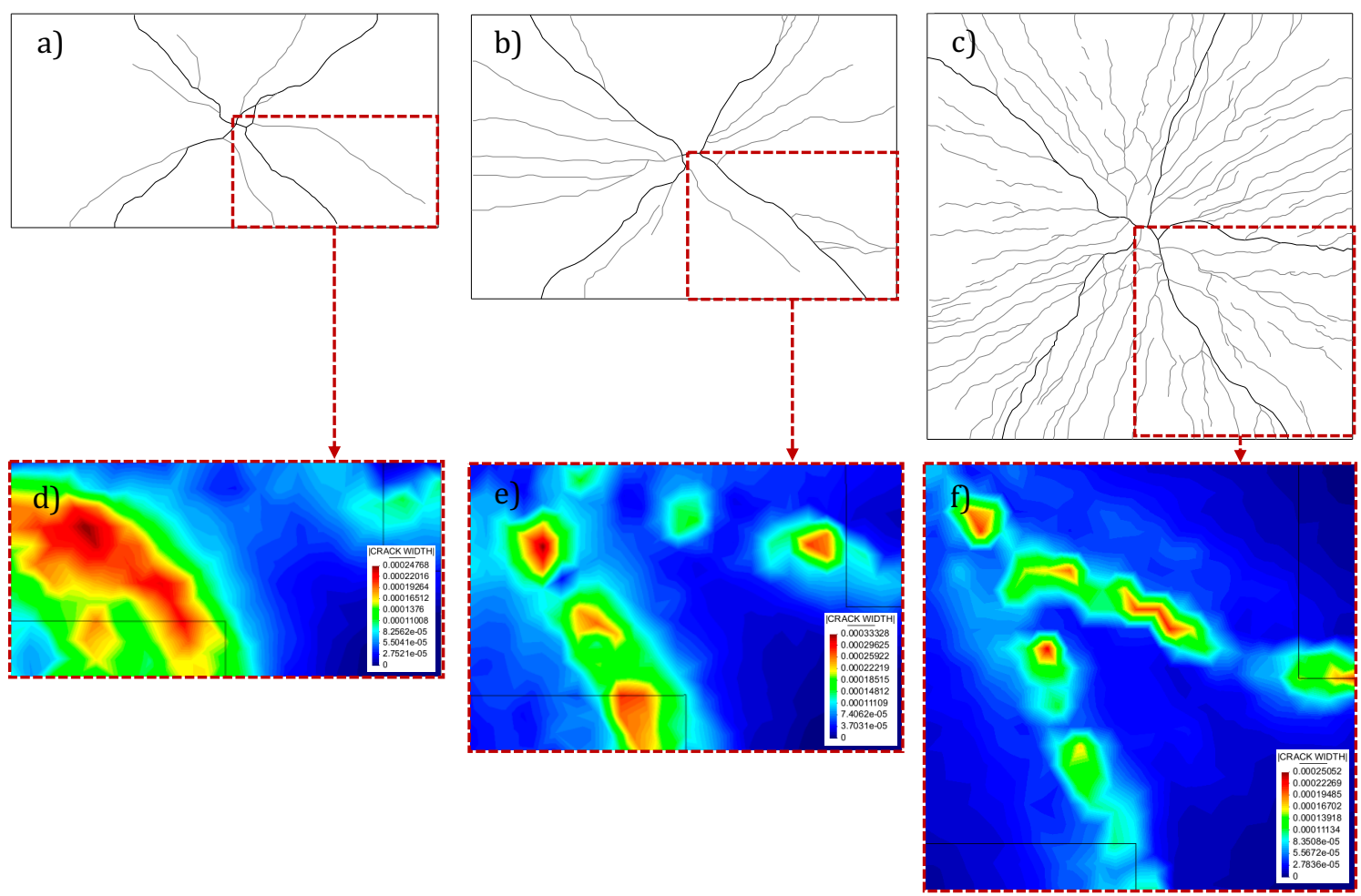

Figure 4. Experimental crack patterns for slabs a) $S_{-} A, b$ ) $M_{-} A$ and c) $L_{-} A$ in comparison with the numerical ones for slabs d) $S$, e) $M$ and f) $L$ for the same deflection.

The numerical result of slab S (Figure $4 \mathrm{~b}$ ) reveals a main crack that extends from the centre of the slab to the edge of the longest support. This is consistent with the results observed in the test of slab S_A (see Figure 4d) that presents a main crack at approximately the same location. In the case of the numerical simulations of slab M (Figure 4b), the principal crack is observed near support 1 while another crack starts to grow towards support 2 (the shortest). This is consistent with the experimental crack pattern of slab M_A presented in Figure 4e. The same is verified for slab L, even though the main cracks are less evident in this case due to the existence of secondary cracks.

All these observations indicate that, in general, the numerical models proposed reproduce adequately the cracking observed experimentally. However, it is necessary to analyse whether the results in terms of load and deflections fit the experimental data. 


\section{$3.2 P-\delta$ curves}

In Figure 5, the $P-\delta$ curves obtained with the RILEM and the EHE models are plotted together with the experimental results for each size of slab. A clear overestimation of the experimental results is observed in all cases. Furthermore, the zoom-in of the curves in the elastic regime (see Figures $5 \mathrm{~d}, 5 \mathrm{e}$ and $5 \mathrm{f}$ ) reveals that this stage is satisfactorily predicted by the numerical model. In fact, the differences in the behaviour only occur after the cracking of the matrix takes place.
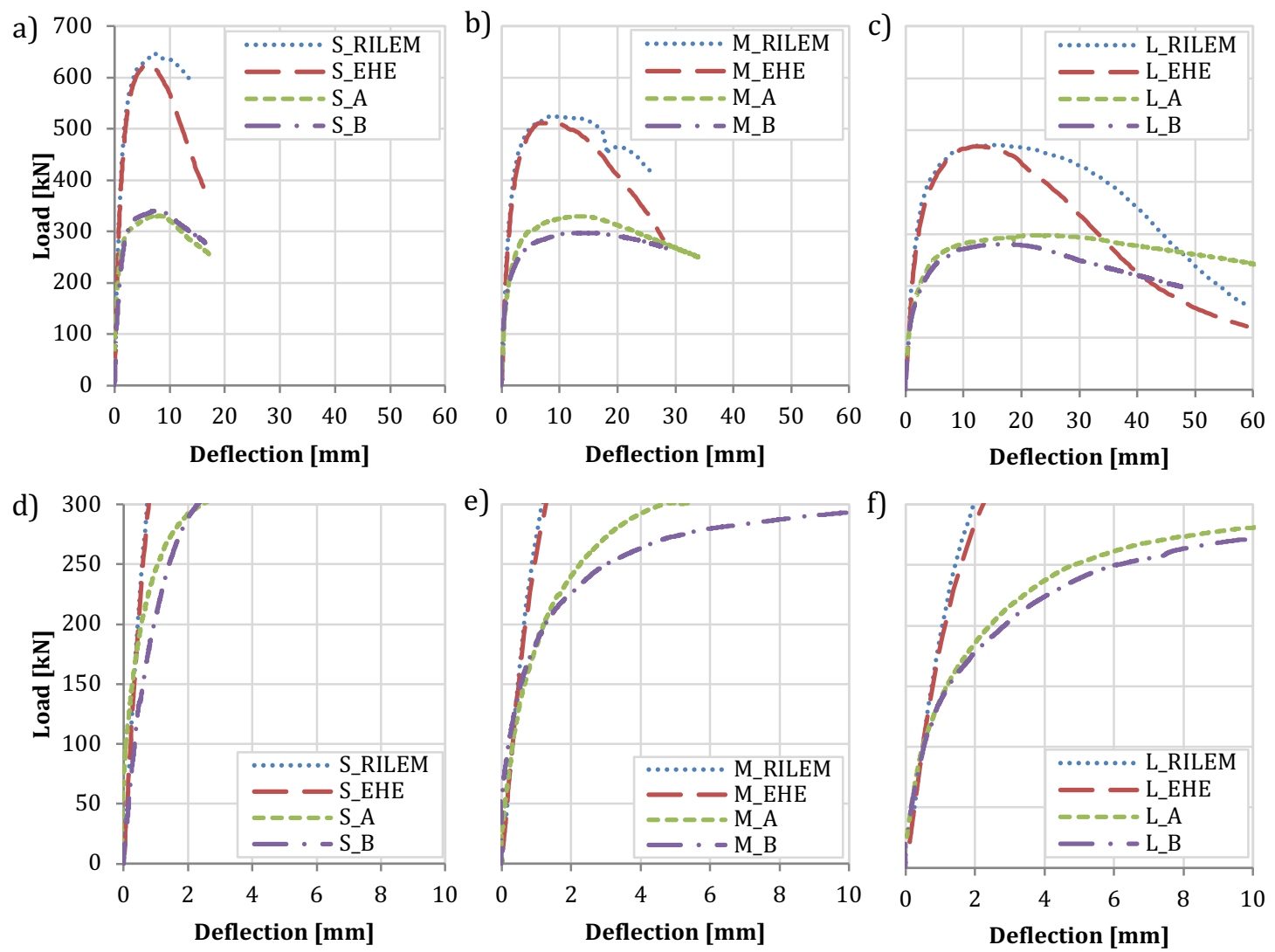

Figure 5. Experimental $P$ - $\delta$ curves and simulation with the RILEM and the EHE diagrams for slabs a) $S$, b) $M$ and c) $L$ and zoom-in of the elastic regime for d) $S$, e) $M$ and f) $L$.

The models with the equations from RILEM and EHE provide very similar curves until the maximum load is reached. Afterwards, the overestimation is greater for the RILEM model. This may be attributed to the higher values of tensile strength and residual strength at ultimate strain observed in the constitutive equation from RILEM, as already highlighted in Figure $3 b$.

Other results derived from the $P-\delta$ curves (such as maximum load, slopes and absorbed energy) are presented in Table 3. Notice that the values of slope correspond to the final stretch of the curve, whereas the energy absorption is considered as the area enclosed by the $P-\delta$ curves for the maximum deflection reached in each size of slab $(15 \mathrm{~mm}, 25 \mathrm{~mm}$ and $45 \mathrm{~mm}$ for slabs $\mathrm{S}, \mathrm{M}$ and $\mathrm{L}$, respectively). 
Table 3. Other results derived from the $P-\delta$ curves of numerical models and experimental results.

\begin{tabular}{ccccccc}
\hline Cases & $\begin{array}{c}\text { Max. load } \\
{[\mathbf{k N ]}}\end{array}$ & $\begin{array}{c}\text { Deflection at } \\
\text { max. load } \\
{[\mathbf{m m}]}\end{array}$ & $\begin{array}{c}\text { Load for } \\
\boldsymbol{\delta = 5} \mathbf{~ m m} \\
{[\mathbf{k N}]}\end{array}$ & $\begin{array}{c}\text { Load for } \\
\boldsymbol{\delta = 1 0 ~ m m} \\
{[\mathbf{k N}]}\end{array}$ & $\begin{array}{c}\text { Slope } \\
{[\mathbf{k N} / \mathbf{m m}]}\end{array}$ & $\begin{array}{c}\text { Energy } \\
\text { absorption } \\
{[\mathbf{J}]}\end{array}$ \\
\hline S_RILEM & 646.7 & 7.3 & 625.1 & 634.7 & -11.5 & 8158.1 \\
S_EHE & 625.0 & 6.1 & 618.5 & 572.2 & -29.7 & 7844.0 \\
Exper. S & 335.5 & 7.8 & 325.9 & 326.0 & -8.5 & 4532.6 \\
\hline M_RILEM & 525.3 & 8.9 & 500.7 & 524.3 & -9.2 & 11668.8 \\
M_EHE & 511.9 & 8.9 & 492.0 & 511.3 & -15.7 & 10897.8 \\
Exper. M & 313.5 & 14.2 & 287.0 & 309.3 & -3.9 & 7213.1 \\
L_RILEM & 471.6 & 15.3 & 410.4 & 464.5 & -11.0 & 18448.1 \\
L_EHE & 468.4 & 12.0 & 402.8 & 464.1 & -7.7 & 15858.4 \\
Exper. L & 288.6 & 19.6 & 245.2 & 276.0 & -2.5 & 11692.1 \\
\hline
\end{tabular}

In terms of the maximum load, the prediction provided by the RILEM and the EHE diagrams approach the experimental data as the width of the slabs increases. In other words, the overestimation is highest for the slabs $\mathrm{S}$ and lowest for the slabs L. A similar trend is observed in Table 3 for the values of load at the deflections of $5 \mathrm{~mm}$ and $10 \mathrm{~mm}$. For instance, in the case of $10 \mathrm{~mm}$, the overestimation of the slabs $\mathrm{S}$ is $94.7 \%$ and $75.5 \%$ with the RILEM and the EHE diagrams, respectively. These values are reduced to $69.5 \%$ and $65.3 \%$, in the case of the M slabs, and to $68.3 \%$ and $68.2 \%$, in the case of the slabs $\mathrm{L}$.

The deflection corresponding to the maximum load provided by the models with the RILEM and the EHE are systematically lower than the ones registered during the tests. The underestimations for the slabs S are $6.6 \%$ and $22.8 \%$, for the slabs $\mathrm{M}$ are $37.2 \%$ and $37.5 \%$ and for the slabs L are $22.1 \%$ and $38.8 \%$, considering the models with the RILEM and the EHE, respectively.

The prediction with the RILEM and the EHE diagrams present, in general, a steeper slope than the observed experimentally. The differences with the experimental results reach $36.3 \%$ and $250.6 \%$ in the case of slab S, $137.0 \%$ and $303.9 \%$ in the case of slab $\mathrm{M}$ and $341.9 \%$ and $209.6 \%$ in the case of slab L, for the RILEM and the EHE models, respectively. The errors in the prediction of energy absorption follow the same trend described for the maximum load with biggest overestimation for the slabs $\mathrm{S}$ and smallest overestimations for the slabs $\mathrm{L}$.

In view of the $P-\delta$ curves in Figure 5 and the results presented in Table 3, it may be concluded that the constitutive models based on the performance of small beams, such as the included in the RILEM and the EHE may not be suitable for the design of SFRC slabs. A numerical fit is conducted to determine the values of the parameters from the constitutive diagram that fit the experimental response of the slabs. Prior to that, a parametric study is performed to evaluate how these parameters affect the structural response of the slabs.

\section{Parametric study}

\subsection{Variables of the study}

In order to simplify the study, it was decided that the parameters $\sigma_{1}$ and $\varepsilon_{1}$, which correspond to the cracking of the concrete matrix, would remain constant given that the fibres only become active after cracking occurs. The parameter $\varepsilon_{3}$ was also considered constant since a preliminary study showed that its influence on the behaviour of the slab 
was minimal. Based on the results presented by Blanco (2013) and the philosophy of the design from the EHE, the parameters $\sigma_{1}, \varepsilon_{1}$ and $\varepsilon_{3}$ were set to $2.879 \mathrm{MPa}, 0.099 \%$ and 20.0 $\%$, respectively. These values do not differ significantly from the obtained with other recent constitutive models, such as the Italian guidelines (CNR-DT 204 2006) or the Model Code 2010 or MC2010 (fib 2010), as reported in previous studies (Blanco et al. 2013).

Table 4 shows the variables analysed in the parametric study $\left(\sigma_{2}, \sigma_{3}\right.$ and $\left.\varepsilon_{2}\right)$. In order to obtain comparable results, the same values were considered for the three slabs. The combination of them led to 150 cases for each type of slab (450 in total). Notice that one of the values selected for $\varepsilon_{2}$ is $0.099 \%$, which corresponds to $\varepsilon_{1}$. However, for notation purposes it is presented as $0.1 \%$.

Table 4. Variables of the parametric study for slabs $S, M$ and $L$.

\begin{tabular}{cccccccc}
\hline Variables & Units & \multicolumn{7}{c}{ Values } \\
\hline$\sigma_{2} / \sigma_{1}$ & {$[-]$} & 0.30 & 0.40 & 0.50 & 0.60 & 0.70 & 0.80 \\
$\sigma_{3} / \sigma_{2}$ & {$[-]$} & 0.50 & 0.65 & 0.80 & 0.95 & 1.10 & - \\
$\varepsilon_{2}$ & {$[\% 0]$} & 0.10 & 0.30 & 0.50 & 0.70 & 0.90 & - \\
\hline
\end{tabular}

\subsection{Analysis of the P- $\delta$ curves}

Figure 6 illustrates the influence of the variables $\left(\sigma_{2}, \sigma_{3}\right.$ and $\left.\varepsilon_{2}\right)$ in the P- $\delta$ curves for some of the 450 cases analysed. The parameters that are maintained constant during the analysis are indicated in each graph.
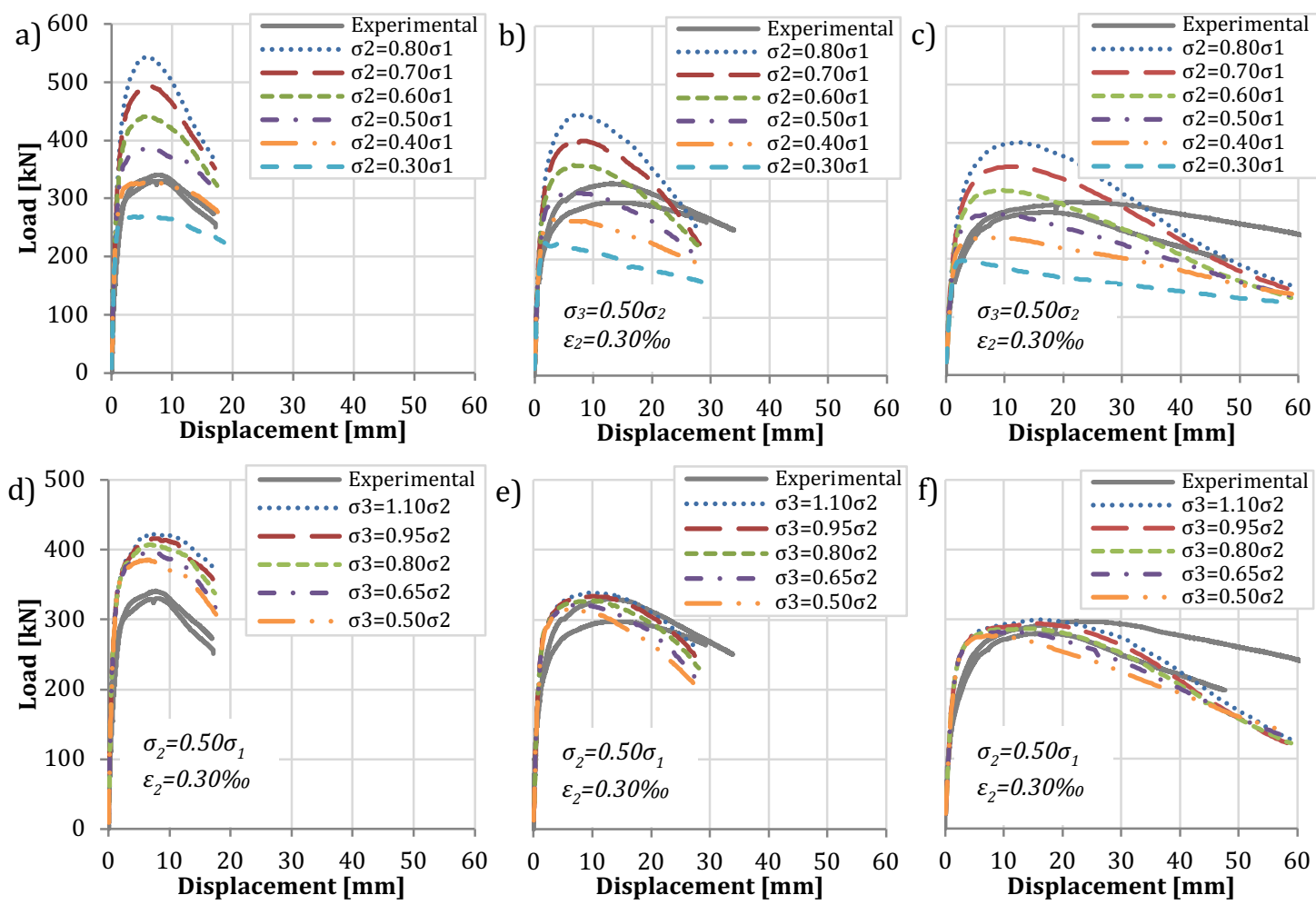

g)

h)

i) 

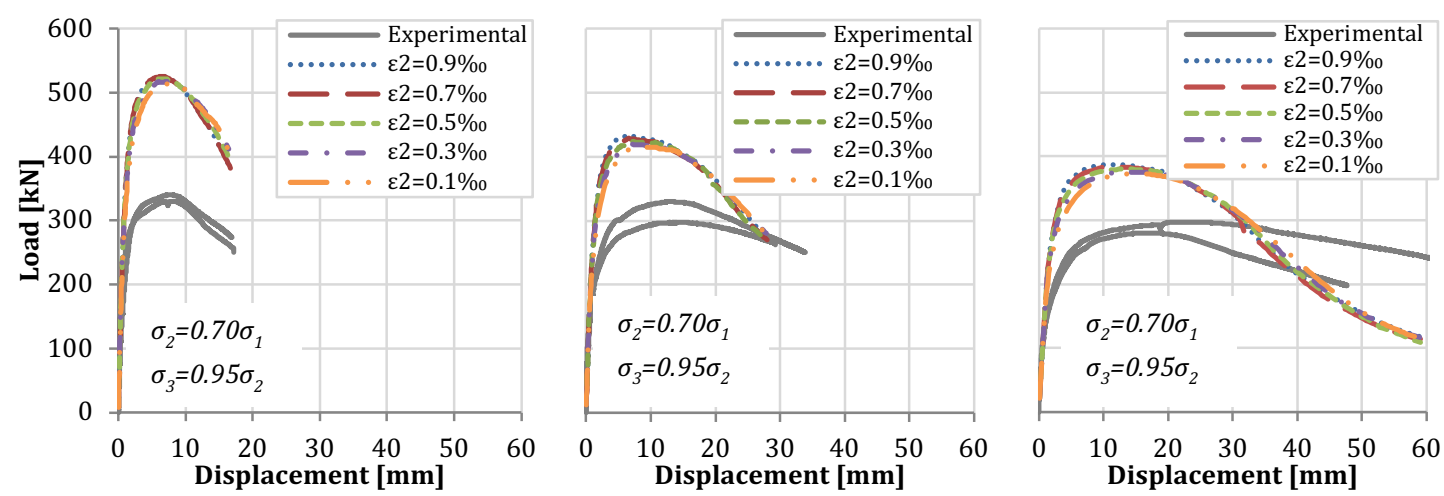

Figure 6. Influence of $\sigma_{2}(a, b$ and $c), \sigma_{3}(d, e$ and $f)$ and $\varepsilon_{2}(g$, $h$ and $i)$ on the $P$ - $\delta$ curves.

The curves of Figure 6 show that the variable that most influences the structural response of the slabs is $\sigma_{2}$. This is particularly evident in the results of maximum load. In addition to that, the results suggest that while $\sigma_{3}$ does have a noticeable influence in the curves, the influence of $\varepsilon_{2}$ seems comparably very small.

\subsection{Analysis of the maximum load}

To further highlight the influence of the variables, in Figure 7, the maximum load from the $P-\delta$ curves presented in Figure 6 are plotted against the values of $\sigma_{2}, \sigma_{3}$ and $\varepsilon_{2}$.
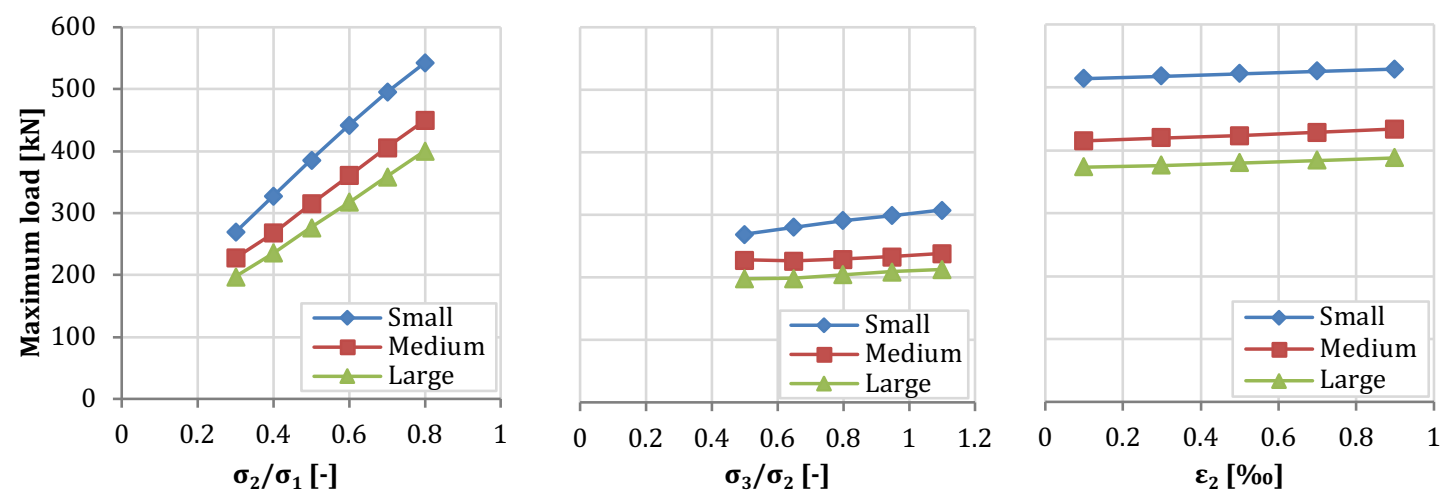

Figure 7. Influence of a) $\left.\sigma_{2}, b\right) \sigma_{3}$, and c) $\varepsilon_{2}$ on the maximum load.

The results indicate that the maximum load increases linearly with $\sigma_{2}, \sigma_{3}$ and $\varepsilon_{2}$. Such increase is more evident in the case of $\sigma_{2}$ and minor in the case of $\varepsilon_{2}$. Notice that a $33 \%$ increase of $\sigma_{2}$ (from 0.3 to 0.4 ) augments the maximum load by $22 \%$; whereas a $200 \%$ increase of $\varepsilon_{2}$ (from $0.1 \%$ to $0.3 \%$ ) only produces a variation of just $1.0 \%$. Likewise, the results suggest that the repercussion of $\sigma_{2}$ and $\sigma_{3}$ becomes greater as the size of the slabs decreases. The same is not so evident for $\varepsilon_{2}$.

\subsection{Analysis of the final slope of the $P-\delta$ curves}

Another parameter which may be significantly affected by the variables of study is the slope of the final stretch in the $P-\delta$ curves that is related with the level of ductility of the structure. Figure 8 shows the relation between such slope and the variables $\sigma_{2}, \sigma_{3}$ and $\varepsilon_{2}$. 


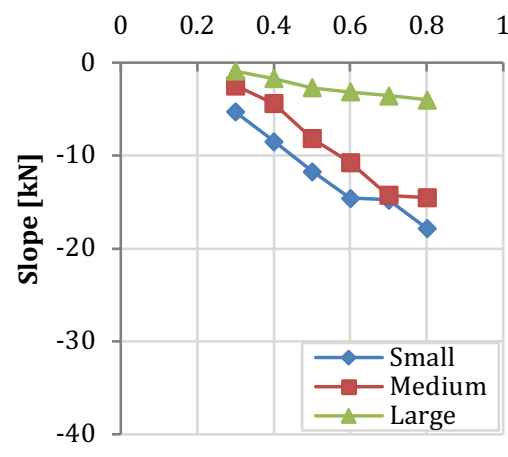

$\sigma_{2} / \sigma_{1}[-]$

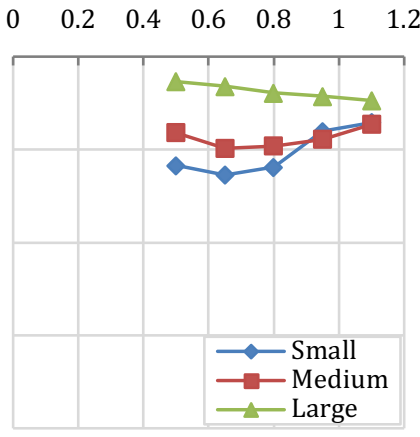

$\sigma_{3} / \sigma_{2}[-]$

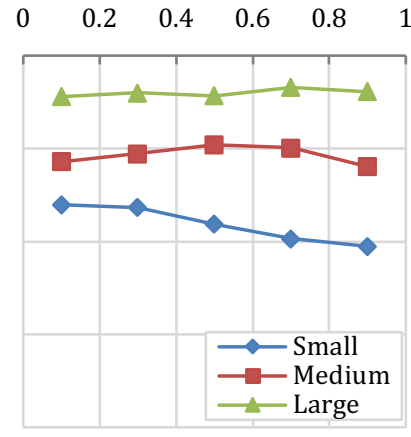

$\varepsilon_{2}[\%$

Figure 8. Influence of a) $\left.\sigma_{2}, b\right) \sigma_{3}$, and c) $\varepsilon_{2}$ on the final slope.

The results suggest a strong influence of $\sigma_{2}$ in the slopes of slabs. Clearly this influence becomes greater as the stiffness of the slab increases. Interestingly, no evident tendencies were found for $\sigma_{3}$ and $\varepsilon_{2}$.

\subsection{Analysis of the absorbed energy}

Figure 9 presents the relation between the absorbed energy up to a displacement of $15 \mathrm{~mm}$ against and the variables of study.
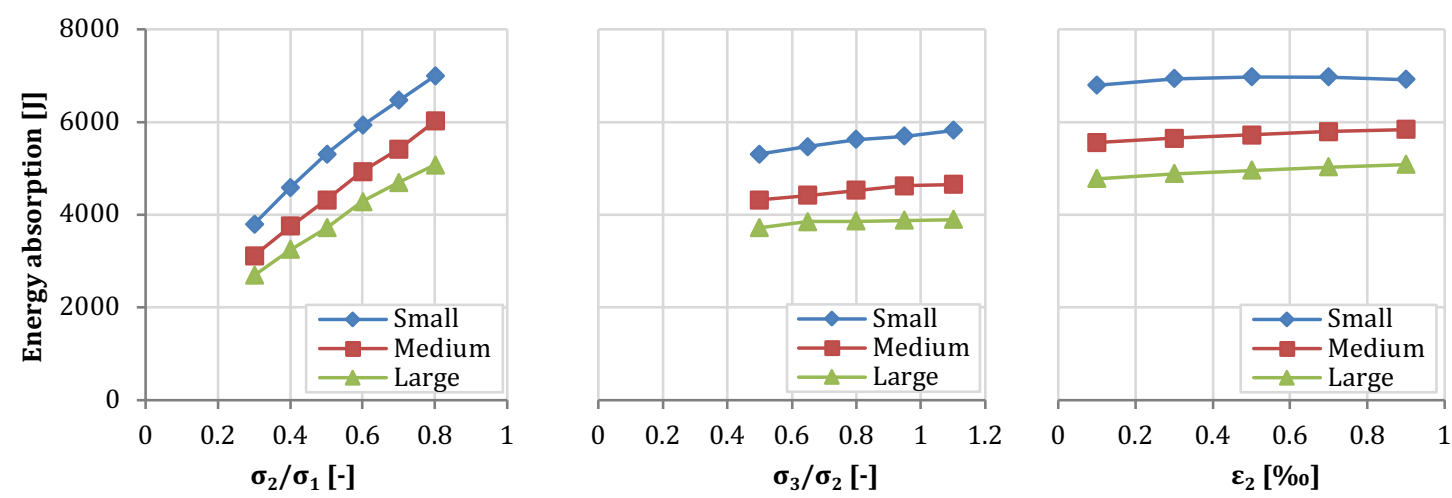

Figure 9 Influence of a) $\left.\sigma_{2}, b\right) \sigma_{3}$, and c) $\varepsilon_{2}$ on the absorbed energy.

It is clear from the curves in Figure 9 that the absorbed energy increases with $\sigma_{2}, \sigma_{3}$ and $\varepsilon_{2}$ for all types of slabs. However, the influence of $\sigma_{2}$ is significantly greater than that of the other variables.

\subsection{Discussion of the results}

The analysis included in the previous sections indicates that $\sigma_{2}$ has a significant influence in the value of maximum load and in the absorbed energy. This parameter is related with the post-cracking strength provided by the fibre reinforcement since, after cracking occurs, the stresses are resisted by their bridging capacity of the fibres (see blue lines in Figure 10). Hence, an increase in $\sigma_{2}$ should lead to higher values of post-cracking strength, of maximum load and of absorbed energy. 


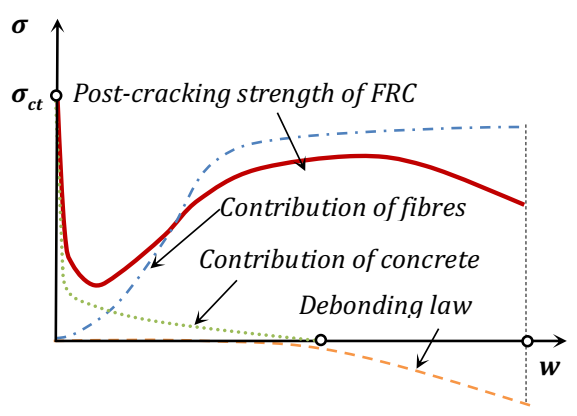

Figure 10. Contribution of the concrete matrix, of the fibre and of the debonding law in the FRC constitutive model according to Laranjeira (2010).

The influence of $\sigma_{2}$ on the maximum load also helps to explain its effect on the slope of the final stretch of the curve. In fact, as higher maximum load is achieved, a more pronounced decrease in the load would be expected for displacements that imply bigger strains. Consequently, steeper slopes should be obtained due to an increase of $\sigma_{2}$. Such phenomenon depends on the geometry and the test setup, which affect the force redistribution capacity of the slabs. In the case of slabs $\mathrm{S}$, with a limited redistribution capacity and a less ductile response, the increase in the maximum load with $\sigma_{2}$ is more noticeable, thus leading to steeper slopes. On the contrary, sabs L exhibit a ductile behaviour and greater redistribution capacity together with smaller increases in the maximum load. Hence, gentler slopes are obtained in this case.

The influence of $\sigma_{3}$ in the behaviour of the slabs is less evident than the observed in the analysis of $\sigma_{2}$. This was expected since $\sigma_{3}$ is not related with the maximum contribution of the fibre but rather with the gradual decrease in the post-cracking strength due to the intensification of the debonding between the fibre and the concrete matrix (see orange curve in Figure 10). Consequently, increases in $\sigma_{3}$ will lead to larger stresses when the pullout mechanisms are activated. Once the debonding starts, a gradual decrease in the postcracking strength occurs (Laranjeira et al. 2010). In this phenomenon, the value of $\sigma_{3}$ will determine the shape of the curve. If high values of $\sigma_{3}$ are considered, higher loads will be reached. Since the energy absorption is measured as the area enclosed by the $P$ - $\delta$ curves, increasing $\sigma_{3}$ will result in greater energy absorption.

On the other hand, the variation in the structural response of the slabs induced by $\varepsilon_{2}$ is very small. In addition to that, the tendency of variation of the post-cracking behaviour (analysed as the slope of the final stretch of the curve) is not clear. Therefore, it may be concluded that the influence of $\varepsilon_{2}$ is negligible in comparison with that of $\sigma_{2}$ or $\sigma_{3}$.

\section{Numerical fit of the experimental curves}

For the numerical fit, the parameters $\sigma_{1}, \varepsilon_{1}$ and $\varepsilon_{3}$ were again fixed with the same values described in section 5.1 (2.879 MPa, 0.099\%o and $20.0 \%$, respectively). Given the minor influence of $\varepsilon_{2}$ on the structural response of the slabs observed in the parametric study, its value was also kept constant. It was defined as $\varepsilon_{2}=\varepsilon_{1}+0.1 \%$, according to the trilinear models of the DBV, the RILEM and the EHE. In other words, only the values of $\sigma_{2}$ and $\sigma_{3}$ were 
varied in an interactive procedure to adjust the results from the model to the obtained in the experimental program. The values finally obtained are presented in Table 6 .

Table 6. Values of the parameters $\sigma_{2}, \sigma_{3}$ and $\varepsilon_{2}$ for slabs $S, M$ and $L$.

\begin{tabular}{ccccc}
\hline Slab & Batch & $\sigma_{2} / \sigma_{1 \text { (EHE) }}$ & $\sigma_{3} / \sigma_{2}$ & $\varepsilon_{2}[\%$ o] \\
\hline $\mathrm{S}$ & $\mathrm{B} 3$ & 0.40 & 0.50 & $\varepsilon_{1}+0.1$ \\
$\mathrm{M}$ & $\mathrm{B} 1$ & 0.47 & 0.95 & $\varepsilon_{1}+0.1$ \\
$\mathrm{~L}$ & $\mathrm{~B} 1$ & 0.57 & 1.00 & $\varepsilon_{1}+0.1$ \\
\hline
\end{tabular}

The $P-\delta$ curves predicted with the values from Table 6 are compared with the experimental results in the graphs in Figure 11.
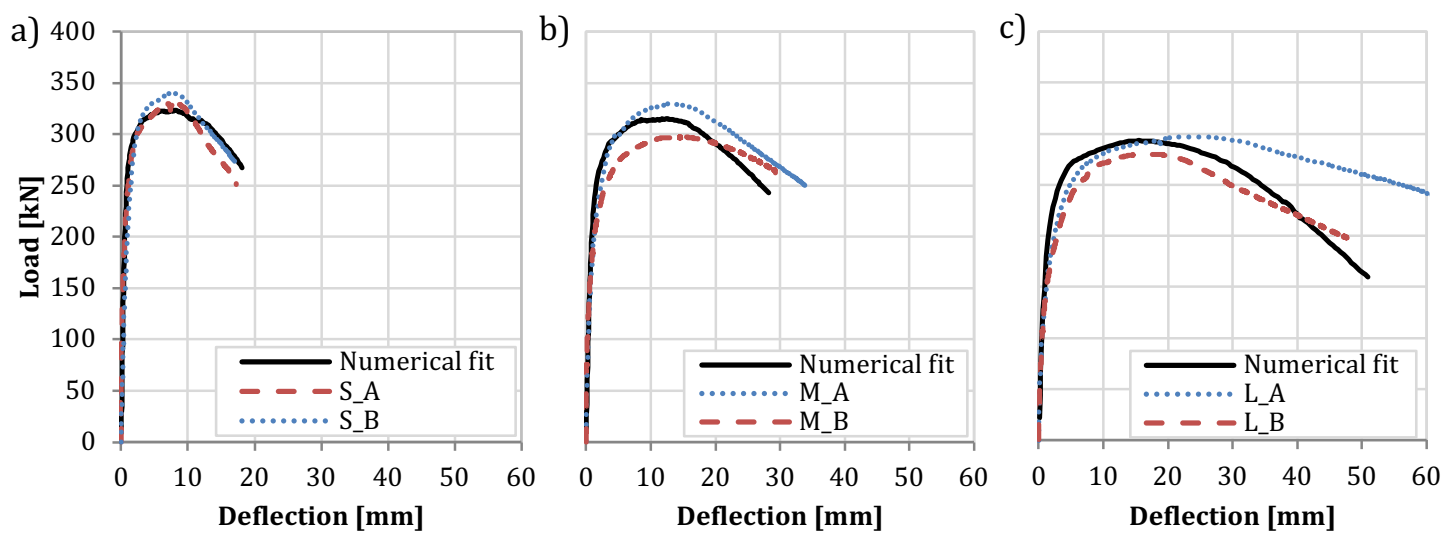

Figure 11. $P$ - $\delta$ curves resulting from the numerical fit of the parameters for slabs a) $S, b) M$ and $c) L$.

Particularly for the slabs S and $\mathrm{M}$, the curve obtained with the numerical model remains between the experimental ones. Slightly bigger differences are observed for slab L. In part, this may be caused by the higher scatter of experimental results for displacements bigger than $30 \mathrm{~mm}$ in this case. To analyse in detail the goodness of the fit, some of the results derived from the $P-\delta$ curves are presented in Table 7. Again, the energy absorption correspond to deflections of $15 \mathrm{~mm}, 25 \mathrm{~mm}$ and $45 \mathrm{~mm}$ for the slabs S, M and L, respectively.

Table 7. Average experimental results and results of the numerical fit.

\begin{tabular}{ccccccc}
\hline Cases & $\begin{array}{c}\text { Max. } \\
\text { load } \\
{[\mathbf{k N}]}\end{array}$ & $\begin{array}{c}\text { Deflection } \\
\text { max. load } \\
{[\mathbf{m m}]}\end{array}$ & $\begin{array}{c}\text { Load for } \\
\boldsymbol{\delta = 5 ~} \mathbf{~ m m} \\
{[\mathbf{k N}]}\end{array}$ & $\begin{array}{c}\text { Load for } \\
\boldsymbol{\delta}=\mathbf{1 0} \mathbf{~ m m} \\
{[\mathbf{k N}]}\end{array}$ & $\begin{array}{c}\text { Slope } \\
{[\mathbf{k N} / \mathbf{m m}]}\end{array}$ & $\begin{array}{c}\text { Energy } \\
\text { absorption } \\
{[\mathbf{J}]}\end{array}$ \\
\hline Exper. S & 335.5 & 7.8 & 325.9 & 326.0 & -8.5 & 4532.6 \\
\hline Numerical fit S & 323.6 & 8.2 & 319.9 & 318.0 & -8.5 & 4516.0 \\
\hline Exper. M & 313.5 & 14.2 & 287.0 & 309.3 & -3.9 & 7213.1 \\
\hline Numerical fit M & 315.1 & 11.8 & 299.6 & 313.3 & -6.4 & 7220.5 \\
\hline Exper. L & 288.6 & 19.6 & 245.2 & 276.0 & -2.5 & 11692.1 \\
\hline Numerical fit L & 293.3 & 15.5 & 268.1 & 285.1 & -5.8 & 11590.8 \\
\hline
\end{tabular}

The numerical result of slab S fits satisfactorily the experimental results measured in the laboratory. The prediction remains on the safe side, exhibiting load values slightly lower than the experimentally registered. For example, an underestimation of $3.5 \%$ is observed for the maximum load. This load occurs at a predicted deflection of $8.2 \mathrm{~mm}$ which is $5.1 \%$ 
higher than the average measured for the slabs S. The numerical fit with the experimental results is also satisfactory for the slope and the energy absorption. In fact, the same value of slope and an underestimation of only $1.3 \%$ of the absorbed energy are observed.

In the case of the slab $M$, the numerical curve obtained with the parameters proposed in Table 6 fit the curves of slab M_A and M_B remarkably well, as observed in Figure 11. The maximum load predicted is almost identical to the average experimental result, which is overestimated by $0.5 \%$. The overestimations of the loads for deflections of $5 \mathrm{~mm}$ and 10 $\mathrm{mm}$ are $4.4 \%$ and $1.3 \%$, respectively. Bigger differences of the values of the deflection are observed for the maximum load and the slope. The former is underestimated by $16.9 \%$ and the latter is overestimated by $64.1 \%$. Despite that, the energy absorption is underestimated only by $0.6 \%$, thus indicating a satisfactory fit between experimental and numerical results.

Regarding the numerical fit of slabs L, it must be pointed out that slabs $L_{-} A$ and $L_{-} B$ presented the greatest differences in the experimental $P$ - $\delta$ curves. Hence, the determination of the parameters of the constitutive diagrams that fit well both slabs is not as straightforward as in slabs S_A and S_B, which are very similar. Despite that, it is considered that the $P$ - $\delta$ curve obtained with the numerical fit approaches well the experimental curves since the maximum load is overestimated by only $1.6 \%$. The overestimation of loads increases slightly for deflections of $5 \mathrm{~mm}$ and $10 \mathrm{~mm}$, reaching $9.3 \%$ and $3.3 \%$, respectively.

Notice that one of the results of the $P$ - $\delta$ curves most difficult to reproduce was the value of slope of the final stretch due to the significant scatter observed in this part of the curve (as shown in Figure 5). This was particularly problematic as the dimensions of the slab increased.

Based on the results presented in Figure 11 and Table 7 it is clear that the proper simulation of the flexural response of the SFRC slabs is possible and requires the definition of specific values for the parameters $\sigma_{2}, \sigma_{3}$ and $\varepsilon_{2}$. These values differ considerably from the predicted with the RILEM and the EHE.

\section{Fibre network effect}

The previous sections confirmed that the constitutive models from the RILEM and the EHE may not be suitable for the design of SFRC slabs considered in this study since they overestimate significantly the real structural response. The $\sigma-\varepsilon$ diagrams obtained for slabs $S, M$ and $L$ after the numerical fit are presented in Figure 12 and Table 6 together with the diagrams calculated originally with the guidelines considered in the study. 

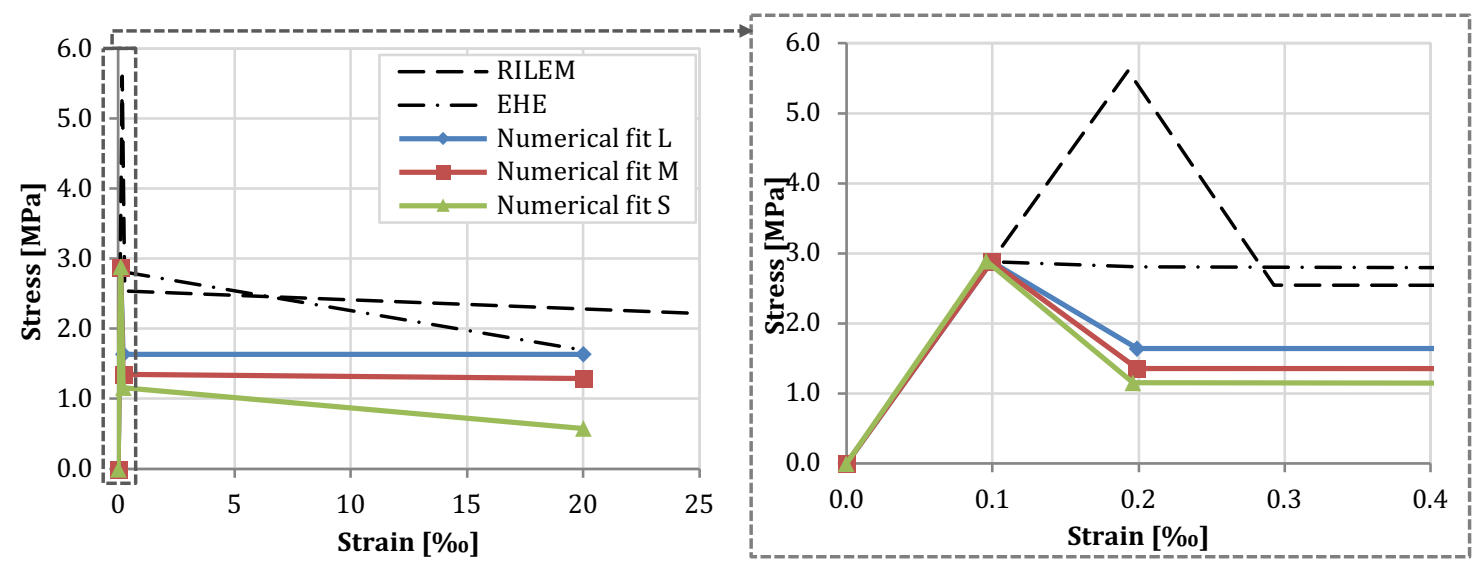

Figure 12. Constitutive models from RILEM, EHE and numerical fit for slabs a) S, b) M and c) $L$.

Table 8. Comparison of the values provided by RILEM and EHE and the numerical fit.

\begin{tabular}{|c|c|c|c|c|c|c|c|}
\hline Slab & $\sigma-\varepsilon$ diagram & $\begin{array}{c}\sigma_{1} \\
{[\mathrm{MPa}]}\end{array}$ & $\begin{array}{c}\sigma_{2} \\
{[\mathrm{MPa}]}\end{array}$ & $\begin{array}{c}\sigma_{3} \\
{[\mathrm{MPa}]}\end{array}$ & $\begin{array}{c}\varepsilon_{1} \\
{[\% 0]}\end{array}$ & $\begin{array}{c}\mathcal{E}_{2} \\
{[\% 00]}\end{array}$ & $\varepsilon_{3}[\% o]$ \\
\hline \multirow{3}{*}{ S } & RILEM & 5.616 & 2.545 & 2.219 & 0.186 & 0.286 & 25.000 \\
\hline & EHE & 2.888 & 2.811 & 1.698 & 0.096 & 0.196 & 20.000 \\
\hline & Numerical fit S & 2.888 & 1.155 & 0.578 & 0.096 & 0.196 & 20.000 \\
\hline \multirow{4}{*}{$M+L$} & RILEM & 5.606 & 2.545 & 2.219 & 0.193 & 0.293 & 25.000 \\
\hline & EHE & 2.879 & 2.811 & 1.698 & 0.099 & 0.199 & 20.000 \\
\hline & Numerical fit M & 2.879 & 1.353 & 1.285 & 0.099 & 0.199 & 20.000 \\
\hline & Numerical fit L & 2.879 & 1.641 & 1.641 & 0.099 & 0.199 & 20.000 \\
\hline
\end{tabular}

The values of $\sigma_{2}$ presented in Table 8 for the numerical fitted curves from slabs $\mathrm{M}$ and $\mathrm{L}$ are $17.1 \%$ and $42.1 \%$ higher than those for slab S. In the case of $\sigma_{3}$, the values increase $122.3 \%$ and $184.0 \%$, respectively. Notice that, although the greatest differences are detected for $\sigma_{3}$, the preliminary study conducted identified $\sigma_{2}$ as the parameter that has the major influence in the flexural response of the slabs.

Table 8 also shows that reductions of $58.9 \%$ and $66.0 \%$ in the values of $\sigma_{2}$ and $\sigma_{3}$ proposed by the EHE are required in order to obtain a good prediction of the flexural response of the slab S. If the comparison is made with the values of the RILEM, the reductions in the stress are $54.6 \%$ and $74.0 \%$ for $\sigma_{2}$ and $\sigma_{3}$, respectively.

For slab M, the values of stress $\sigma_{2}$ and $\sigma_{3}$ proposed by the EHE are reduced by $51.9 \%$ and $24.3 \%$ after the numerical fit, whereas a reduction of respectively $46.8 \%$ and $42.1 \%$ is required in the case of the RILEM. Moreover, the numerical fit for slab L implies a $41.6 \%$ decrease for $\sigma_{2}$ and a 3.4\% increase for $\sigma_{3}$ compared to the EHE. In the case of the values of RILEM, a reduction of $35.5 \%$ and $26.0 \%$ is observed, respectively.

The evident overestimation of $\sigma_{2}$ and $\sigma_{3}$ provided by RILEM and EHE is caused by the differences, in terms of the structural behaviour and the fibre orientation, between the beam used in the characterization test and the slabs tested in the laboratory. On the one hand, the beam presents an isostatic behaviour, while the slab presents hyperstatic response. On the other hand, the orientation in the beam is mainly in one direction, whereas for a slab the fibres align in two directions. 
In view of that, the question that may be raised at this point is why larger slabs present higher values of stress in the $\sigma-\varepsilon$ diagram compared to smaller slabs? According to the literature (Kooiman 2000; Laranjeira 2010), different responses of FRC may be caused by the properties of the concrete matrix affecting the fibre-matrix interface, the fibre orientation and the fibre type and content. Since the properties of the SFRC are practically the same for all slabs, the only difference detected is the orientation of the fibres due to the dimensions of the slabs. This was evidenced in the experimental program from Blanco (2013), which assessed the actual orientation of the fibres in the concrete matrix by drilling cores from the slabs and using a non-destructive magnetic method (Torrents et al. 2012, Cavalaro et al. 2014) to measure their average orientation.

The study suggests that fibres tend to align parallel to the formwork surface due to the walleffect. Fibres also tend to rotate and align perpendicular to the flow of concrete as the material moves from the pouring position to the edges of the formwork. It is important to remark that this finding is line with other works from the literature that focus on SFRC subjected to radial flow (Grünewald 2004; Boulekbache et al. 2010; Martinie and Roussel 2011).

Figure 13 illustrates schematically the concrete radial flow in a smaller rectangular slab (see Figure 13a), such as slab S, and in a larger square slab (see Figure 13b), such as slab L. In the latter case, the concrete tend to flow regularly in all directions and the fibres align perpendicularly to the direction of the flow. On the contrary, in the smaller slab the way the concrete flows is not regular since it is affected by the shorter size. Consequently the material flow path should be larger for the longest dimension, meaning that relative more fibres are affected by the wall-effect (in the case of Figure 13a).
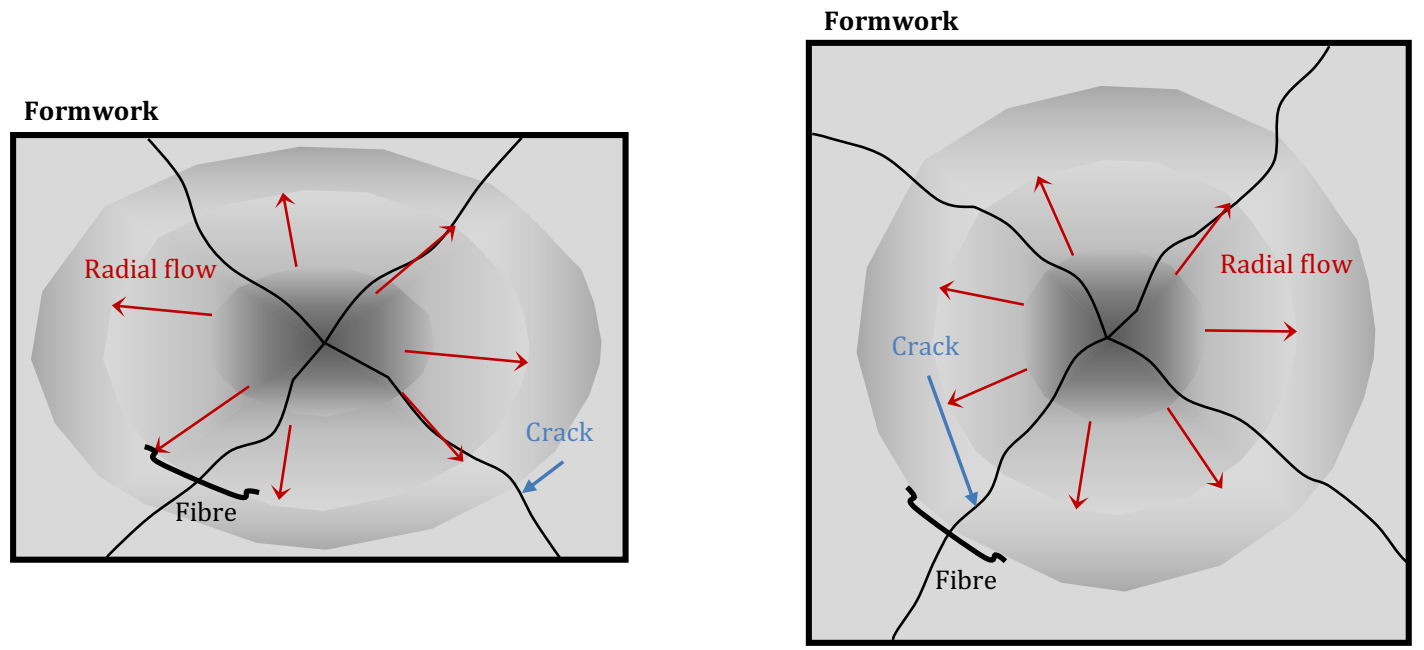

Figure 13. Fibre orientation in a) a smaller rectangular slab and b) a larger square slab.

Consider now the crack pattern described in section 4.1. As depicted in Figure 13, the way fibres align (perpendicularly to the flow) should be more advantageous in the case of the largest slab from Figure 13b. In this situation, fibres are more likely to be positioned perpendicular to the cracks, assuming a more efficient orientation regarding the cracking plane. Therefore, higher stress bearing capacity of FRC at a sectional level should be 
expected due to a more favourable orientation of the fibres with regards to the failure plane in comparison with the observed in the small rectangular slab.

This phenomenon - referred hereinafter as fibre network effect - would be of great interest if quantified and considered in the design. Even though the number of tests performed in this study is not enough to propose an integrated methodology for the design of slabs taking into account fibre orientation, a simplified approach may be suggested for future research.

Given that the main differences among the numerical fits of each slab correspond to the values of $\sigma_{2}$ and $\sigma_{3}$, the fibre network effect should be assessed through these parameters. For that, the values of $\sigma_{2}$ and $\sigma_{3}$ from the numerical fit of slabs $\mathrm{M}$ and $\mathrm{L}$ are compared with the values of $\sigma_{2}$ and $\sigma_{3}$ for slab S in terms of their ratio, as indicated by (Eq.1) and (Eq.2).

$$
\begin{aligned}
& \eta_{f \sigma_{2}}=\frac{\sigma_{2 i}}{\sigma_{2 S}} \text { for } i=M, L \\
& \eta_{f \sigma_{3}}=\frac{\sigma_{3 i}}{\sigma_{3 S}} \text { for } i=M, L
\end{aligned}
$$

In this context, the ratios $\eta_{f \sigma 2}$ and $\eta_{f \sigma 3}$ represent the increase on load bearing capacity observed at the sectional level as a result of the slab geometry, thus indicating the amount fibre network effect generated relatively to slab $\mathrm{S}$. The values of these factors are presented in Table 9.

Table 9. Fibre network effect factors for the slabs $S, M$ and $L$.

\begin{tabular}{ccccc}
\hline Slab & $\begin{array}{c}\text { Width } \\
{[\mathbf{m}]}\end{array}$ & $\begin{array}{c}\text { Width/Length } \\
{[-]}\end{array}$ & $\begin{array}{c}\boldsymbol{\eta}_{\boldsymbol{f} \boldsymbol{2} 2} \\
{[-]}\end{array}$ & $\begin{array}{c}\boldsymbol{\eta}_{\boldsymbol{f} \boldsymbol{3}} \\
{[-]}\end{array}$ \\
\hline $\mathrm{S}$ & 1.5 & 0.50 & 1.00 & 1.00 \\
$\mathrm{M}$ & 2.0 & 0.67 & 1.17 & 2.23 \\
$\mathrm{~L}$ & 3.0 & 1.00 & 1.42 & 2.84 \\
\hline
\end{tabular}

Even though theoretically attributed to a certain fibre orientation, it should be remarked that the degree of hyperstaticity of the structure or the size of the element could influence the fibre network effect. The ultimate goal would be to derive a general expression able to quantify this effect in a simplified way. Nevertheless, many more experimental programs with real-scale SFRC elements are yet required for that purpose. In particular, the repercussion of the fibre content or the support condition on the fibre network effect should be verified. Likewise, further tests should be performed with slabs with different dimension in order to determine the limits of the fibre network effect and derive general equations.

\section{Conclusions}

The study conducted in this paper revealed that the direct application of the constitutive models based on bending tests may not be the most suitable alternative for the design of SFRC slabs. In fact, the results of the numerical simulations performed with these models overestimate the structural response measured in the experimental program. In terms of the maximum load, such overestimation may reach values over $60 \%$. This may be attributed to the low representativeness of the beam test as a method for the characterization of the 
flexural behaviour of the slabs, as well as to the absence of corrections factors applied to the SFRC constitutive models that account for the special characteristics of the real-scale element. Such results suggest the need to use geometry factors for elements with shapes different from the bending test.

The parametric study performed with the trilinear constitutive diagram (defined by the parameters $\sigma_{1}, \sigma_{2}, \sigma_{3}, \varepsilon_{1}, \varepsilon_{2}$ and $\varepsilon_{3}$ ) showed that the stress $\sigma_{2}$ is the parameter with the biggest influence over the structural response of the slabs (notice that $\sigma_{1}, \varepsilon_{1}$ and $\varepsilon_{3}$ were kept constant in the study). This parameter affects particularly the maximum load and the energy absorption capacity. On the contrary, the strain $\varepsilon_{2}$ leads to minor changes in the response if compared to the repercussion of $\sigma_{2}$ or $\sigma_{3}$.

The study also shows the influence of a certain fibre orientation in the structural response of the slabs. In this regard, the most significant contribution is the observation of a fibre network effect that leads to an enhanced sectional response as the ratio width/length of the slabs increases. This phenomenon, attributed to the favourable orientation of the fibres regarding the cracking plane, may be of great interest for an optimized design of SFRC structures. Even though a simplified approach was suggested to quantify this effect, further research should be conducted in order to implement it in design codes and guidelines.

\section{Acknowledgements}

The authors of this document wish to show their gratitude for the economic support received through the Research Project BIA2010-17478: Construction processes by means of fibre reinforced concretes. The first author acknowledge the grant FI provided by the Comissionat per a Universitats del DIUE de la Generalitat de Catalunya i del Fons Social Europeu and the support of the Col-legi d'Enginyers de Camins, Canals i Ports de Catalunya.

\section{References}

AENOR. UNE 83507:2004 (2004) Hormigones con fibras. Rotura por compresión. Asociación Española de Normalización y Certificación, Madrid (In Spanish).

AENOR. UNE 83316:1996 (1996) Ensayos de hormigón. Determinación del módulo de elasticidad en compresión., Asociación Española de Normalización y Certificación, Madrid (In Spanish).

AFGC-SETRA. Ultra high performance fibre-reinforced concretes, interim recommendations. AFGC Publication, France, 2002.

Barnett S, Lataste J-F, Parry T, Millard S, Soutsos M. Assessment of fibre orientation in ultra high performance fibre reinforced concrete and its effect on flexural strength. Mater Struct 2010; 43(7):1009-1023.

Barros JAO, Cunha V, Ribeiro A, Antunes J. Post-cracking behaviour of steel fibre reinforced concrete. Mater Struct 2005; 38(1): 47-56.

Blanco A. Characterisation and modelling of SFRC elements, Doctoral Thesis, Universitat Politècnica de Catalunya, Barcelona, 2013.

Blanco A, Pujadas P, de la Fuente A, Cavalaro S, Aguado A. Application of constitutive models in European codes to RC-FRC. Constr Build Mater 2013; 40: 246-59.

Boulekbache B, Hamrat M, Chemrouk M, Amziane S. Flowability of fibre-reinforced concrete and its effect on the mechanical properties of the material. Constr Build Mater 2010; 24(9):1664-71.

Casanova P, Rossi P. Analysis and design of SFRC beams. ACI Struct J 1997; 94(5):595-624. 
CENa. EN1337-3:2005 Structural bearings- Part 3: Elastomeric bearings, European Committee for Standarization, Brussels, 2005.

CENb. EN 14651:2005 Test method for metallic fibrered concrete - Measuring the flexural tensile strength (limit of proportionality (LOP), residual), European Committee for Standardization, Brussels, 2005.

Cervenka, V. Simulating a response. Concr Eng Int 2000; 4(4):45-9.

CNR. CNR-DT 204 /2006 Guide for the Design and Construction of Fiber-Reinforced Concrete Structures, Italian National Research Council, Rome, 2006.

CPH. Instrucción del Hormigón Estructural EHE-08, Ministerio de Fomento, Madrid, 2008.

DBV. Guide to Good Practice "Steel Fibre Concrete", German Society for Concrete and Construction Technology, Berlin, 2001.

de la Fuente A, Pujadas P, Blanco A, Aguado A. Experiences in Barcelona with the use of fibres in segmental linings. Tunnelling Underground Space Technol 2012; 27(1):60-71.

de Montaignac R, Massicotte B, Charron J-P, Nour A. Design of SFRC structural elements: flexural behavior prediction. Mater Struct 2012; 45(4):623-636.

Destrée, X. and Mandl, J. Steel fibre only reinforced concrete in free suspended elevated slabs: Case studies, design assisted by testing route, comparison to the latest SFRC standard documents. In Proceedings of the fib Symposium "Tailor Made Concrete Structures", Amsterdam, 2008, Walraven Stoelhost Eds. Taylor \& Francis Group.

fib. Model Code 2010, International Federation for Structural Concrete, Lausanne, 2010.

Grünewald S. Performance-based design of self-compacting fibre reinforced concrete. Doctoral Thesis, Delft University of Technology, Delft, 2004.

Habel K. Structural behaviour of elements combining UHPFRC and reinforced, Doctoral Thesis, École Polytechnique Fédérale de Lausanne, Laussanne, 2004.

IBN. NBN B 15-238 Essais des bétons renforcés de fibres - Essai de flexion sur éprouvettes prismatiques, Institut Belge de Normalisation Brussels, 1992.

Iyengar SRKT, Raviraj S, Ravikumar P. Analysis study of fictitious crack propagation in concrete beams using a bi-linear $\mathrm{r}-\mathrm{w}$ relation. In: 3th International conference on fracture mechanics of concrete and structure (FRAMCOS III), Japan, 1998, 315-324.

Kooiman AG. Modelling Steel Fibre Reinforced Concrete for Structural Design. Doctoral Thesis, Delft University of Technology, Delft, 2000.

Laranjeira F, Aguado A, Molins C. Predicting the pullout response of inclined straight steel fibers, Mater Struct 2010; 43:875-895.

Laranjeira F. Design-oriented constitutive model for steel fiber reinforced concrete, Doctoral Thesis, Universitat Politècnica de Catalunya, Barcelona, 2010.

Martinie L, Roussel N. Simple tools for fiber orientation prediction in industrial practice, Cem Concr Res 2011, 41(10):993-1000.

Massicotte B. Implementing SFRC design into North American codes: application to a building floor. Invited paper to the International workshop on the advanced in fibre reinforced concrete, Bergamo, Italia, 2004, September 24-25, pp 73-80.

Michels J, Waldmann D, Maas S, Zürbes A. Steel fibers as only reinforcement for flat slab construction - Experimental investigation and design. Constr Build Mater 2012; 26(1):145-55.

Pederson C. New production processes, Materials and Calculation Techniques for Fibre Reinforced Pipes. Doctoral Thesis, Technical University of Denmark, Kongens Lyngby, 1996. 
Plizzari GA, Tiberti G. Steel fibres as reinforcement for precast tunnel segments. Tunnelling Underground Space Technol 2006; 21(3-4):438-9.

RILEM TC 162-TDF - tests and designmethods for steel fibre reinforced concrete: design of steel fibre reinforced concrete using the $\sigma-\mathrm{w}$ method: principles and applications. Mater Struct 2002; 35:262278.

RILEM TC162-TDF. Test and design methods for steel fibre reinforced concrete $-\sigma-\varepsilon$ Design MethodFinal Recommendation. Mater Struct 2003; 36(8):560-7.

Cavalaro S, López R, Torrents JM, Aguado A. Improved assessment of Fibre Content and Orientation with Inductive Method in SFRC. Minor revisions in Mater Struct.

Sorelli LG, Meda A, Plizzari GA. Steel Fiber Concrete Slabs on Ground: A Structural Matter. ACI Struct J 2006; 103(4):551-8.

Stähli P, Custer R, van Mier JGM (2008) On flow properties, fibre distribution, fibre orientation and flexural behaviour of FRC. Mater Struct 41:189-196.

Strack M. Modelling of crack opening of SFRC under tension and bending. In: 7th International Rilem Symposium on FRC: design and application, India, 2008, Gettu Ed., 323-332.

Tlemat H, Pilakoutas K, Neocleous K. Modelling of SFRC using inverse finite element analysis. Mater Struct 2006; 39(2):221-233.

UNI 11188. Design, production and control of steel fibre reinforced structural elements. Italian Board of Standardization, Milan, 2004.

Ultkjaer JP, Krenk S, Brincker R. Analytical model for fictitious crack propagation in concrete beams. ASCE J. Eng Mech 1995; 121(1):7-15 